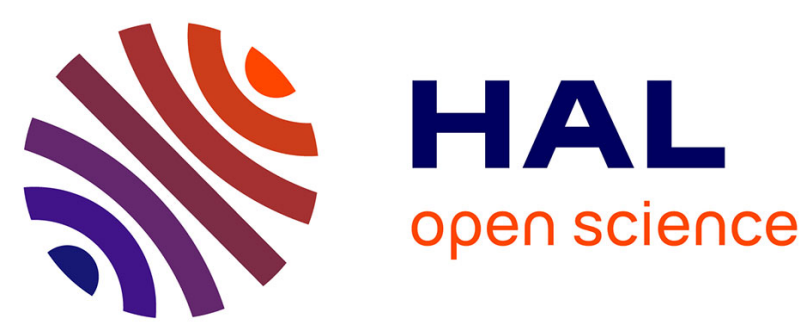

\title{
SYNTHESIS AND CHEMISTRY OF THE NEW Y-BASED AND Bi-BASED HIGH TEMPERATURE SUPERCONDUCTING PEROVSKITES
}

J.-M. Tarascon, P. Barboux, P. Miceli, B. Bagley, L. Greene, G. Hull, M. Giroud

\section{To cite this version:}

J.-M. Tarascon, P. Barboux, P. Miceli, B. Bagley, L. Greene, et al.. SYNTHESIS AND CHEMISTRY OF THE NEW Y-BASED AND Bi-BASED HIGH TEMPERATURE SUPERCONDUCTING PEROVSKITES. Journal de Physique Colloques, 1988, 49 (C8), pp.C8-2081-C8-2086. 10.1051/jphyscol:19888942 . jpa-00229221

\section{HAL Id: jpa-00229221 https://hal.science/jpa-00229221}

Submitted on 1 Jan 1988

HAL is a multi-disciplinary open access archive for the deposit and dissemination of scientific research documents, whether they are published or not. The documents may come from teaching and research institutions in France or abroad, or from public or private research centers.
L'archive ouverte pluridisciplinaire HAL, est destinée au dépôt et à la diffusion de documents scientifiques de niveau recherche, publiés ou non, émanant des établissements d'enseignement et de recherche français ou étrangers, des laboratoires publics ou privés. 


\title{
SYNTHESIS AND CHEMISTRY OF THE NEW Y-BASED AND Bi-BASED HIGH TEMPERATURE SUPERCONDUCTING PEROVSKITES
}

\author{
J. M. Tarascon, P. Barboux, P. F. Miceli, B. G. Bagley, L. H. Greene, G. W. Hull and M. Giroud \\ Bellcore, 331 Newman Springs Road, Red-Bank, New Jersey 07701-7020, U.S.A.
}

\begin{abstract}
Chemical synthesis of the new high $T_{\mathrm{c}}$ oxides using solid state reactions or solution techniques is shown. A solution process which allows the preparation of both homogeneous and dense ceramics and of superconducting thick films has been developed for the $\mathrm{YBa}_{2} \mathrm{Cu}_{3} \mathrm{O}_{7}$ system. Physical measurements performed on homogeneous $\mathrm{YBa}_{2} \mathrm{Cu}_{3-x} \mathrm{Co}_{x} \mathrm{O}_{y}$ samples have shown that the Co substitution, associated with an uptake of oxygen, takes place on the Cu-O chains and that $T_{\mathrm{c}}$ is depressed, leading ultimately to antiferromagnetic insulators whose magnetic structures are shown. Three phase of general formula $\mathrm{Bi}_{2} \mathrm{Sr}_{2} \mathrm{Ca}_{n-1} \mathrm{Cu}_{n} \mathrm{O}_{y}$ with $n=1,2$ and 3 have been isolated in the $\mathrm{Bi}$ system and characterized for their structural and physical properties. These phases crystallize in the same pseudotetragonal unit cell differing one from the next by the stacking sequence along the $c$-axis, with the main feature being the presence of a sheared $\mathrm{Bi}-\mathrm{O}$ double layer. The $T_{\mathrm{c}}^{\prime}$ s of the $n=1,2$ and 3 phases are $10 \mathrm{~K}, 85 \mathrm{~K}$ and $110 \mathrm{~K}$ respectively, but because of phase intergrowth, these values depend upon sample processing, making chemical substitutions within the Bi system quite complex as is discussed. Finally, we succeeded in making superconducting thick films (having zero resistance around $100 \mathrm{~K}$ ) of the Bi-based and T1-based matrials via the decomposition of aqueous-glycerol solutions containing the salts of the elements.
\end{abstract}

\section{Introduction}

Since the discovery of superconductivity at $40 \mathrm{~K}$ in the La-Ba-Cu-O system by Bednorz and Muller [1], much work has been devoted towards the discovery of other high $T_{\mathrm{c}}$ materials in the cuprate oxide family. This was done with the hope of enlarging this class of materials and to provide theorists with more experimental data that could help in the understanding of the origin of superconductivity in these oxides.

New materials have been found and $T_{c}$ was raised from $40 \mathrm{~K}$ to $90 \mathrm{~K}$ with the $\mathrm{YBa}_{2} \mathrm{Cu}_{3} \mathrm{O}_{7-y}$ phase [2] whose structure contains $\mathrm{CuO}_{2}$ planes and $\mathrm{Cu}-\mathrm{O}$ chains [3]. A feature common to both the $40 \mathrm{~K}$ and $90 \mathrm{~K} T_{\mathrm{c}}$ oxides is that they have closely related parent compounds that are antiferromagnetic insulators [4]. Based on these observations it was suggested that magnetism played an important role (e.g., as in the RVB model [5]) and that $\mathrm{Cu}-\mathrm{O}$ chains were required to achieve the high critical temperatures. The recent discovery of superconductivity at $110 \mathrm{~K}$ in a Bi-based material [6] whose structure [7] does not contain chains has shown that the presence of a square planar coordinated copper (i.e. chains) is not necessary. The existence of magnetism within the Bi-based materials is still an unanswered question because of the difficulty encountered in obtaining a pure (free of second phases) insulating material, as will be discussed.

In this paper we stress material problems (namely stoichiometry and intergrowths) that exist for both the $\mathrm{Y}$ - and Bi-based compounds and show that homogeneous samples of $\mathrm{YBa}_{2} \mathrm{Cu}_{3} \mathrm{O}_{y}$ can be prepared by a "sol-gel" process. A study of the $\mathrm{YBa}_{2} \mathrm{Cu}_{3-x} \mathrm{Co}_{x} \mathrm{O}_{y}$ series is presented to emphasize that reliable measurements can be obtained on homogeneous samples.
With the Bi-based materials, solid state reactions have been used to isolate the 3 phases of general formula $\mathrm{Bi}_{2} \mathrm{Sr}_{2} \mathrm{Ca}_{n-1} \mathrm{Cu}_{n} \mathrm{O}_{y}$ with $n=1,2$, and 3 and a solution technique has been developped to produce superconducting thick films of $\mathrm{Bi}$ and $\mathrm{T} 1$ cuprate oxides.

\section{Y-based materials}

2.1 SYNTHESIS. - The materials are usually made (solid state reaction) by heating a mixture of $\mathrm{Y}_{2} \mathrm{O}_{3}$, $\mathrm{CuO}$, and $\mathrm{BaCO}_{3}$ or $\mathrm{Ba}\left(\mathrm{NO}_{3}\right)_{2}$ powders at a temperature of $950{ }^{\circ} \mathrm{C}$ for several hours and cooling slowly in an oxygen atmosphere. The resulting ceramics superconduct at $90 \mathrm{~K}$, but are of low density and exhibit a low critical current $J_{\mathrm{c}}\left(500 \mathrm{Amp} / \mathrm{cm}^{2}\right)$. A low $J_{\mathrm{c}}$ is usually ascribed to inhomogeneities within the sample. Solution chemistry, which allows a mixing at the molecular level, is known to produce a better ceramic. We succeeded in preparing the 123 material using solution techniques (Sol-Gel process) [8, 9]. Gels of the 123 have been obtained by mixing appropriate amounts of copper acetate, barium hydroxide and barium acetate with colloidal $\mathrm{Y}(\mathrm{OH})_{3}$ at a $\mathrm{pH}$ close to 7 . The resulting gels can be dried to produce glassy-like materials which, after firing, give the 123 phase with a $T_{\mathrm{c}}$ of $92 \mathrm{~K}$ and a delta $T_{\mathrm{c}}$ (defined as $10 \%-90 \%$ of the resistive transition) of $0.6 \mathrm{~K}$. It is important to note that, although reagent grade materials are used, this is one of the sharpest transitions measured on a bulk ceramic. The $T_{\mathrm{c}}$ is slightly lower $(2 \mathrm{~K})$ than that measured on solid state derived ceramics and we believe this is due to impurities in the starting reagents. For instance, the main impurity in the $\mathrm{BaCO}_{3}$ used is strontium carbonate and we have previously shown 
[10] that the substitution of $\mathrm{Ba}$ by $\mathrm{Sr}$ in the $123 \mathrm{ma}-$ terial slightly depresses $T_{c}$. Impurities would also be expected to broaden the superconducting transition. The observed sharpness of the transition indicates that the impurities are evenly distributed throughout the sample (i.e. it is very homogeneous). From resistivity measurements performed on single crystals, the value of the resistivity expected for a polycrystalline dense ceramic (applying the effective medium field theory [11]) is close to that observed for our solution derived material. This implies that, using this process, we can produce a ceramic whose superconducting properties tend towards those of a single crystal. However, the critical current measured on these sol-gel derived ceramics is low and never exceeds $1000 \mathrm{Amp} / \mathrm{cm}^{2}$.

Painting the gels on various substrates, followed by a rapid firing, produces superconducting thick films (1 to 50 microns) with $T_{c}^{\prime} \mathrm{s} 10 \mathrm{~K}$ lower than for the $10 \mathrm{~K}$ lower than for the bulk (Fig. 1). One advantage of this thick film process is that we are certain of the composition and properties of the gel-derived bulk, so that, by comparison it is easier to study and control the interactions with the substrate of the gel-derived thick film.

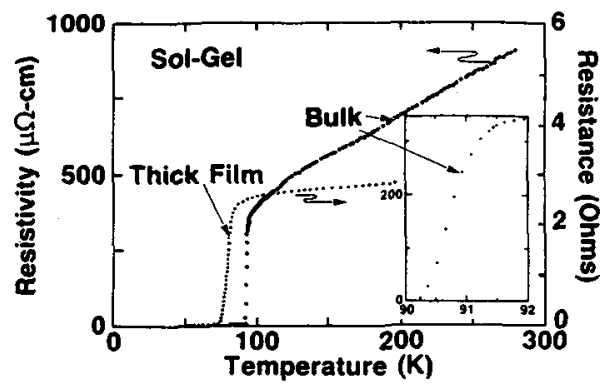

Fig. 1. - The resistivity for a $90 \%$ dense ceramic and the resistance of a 2 micron thick film on a $\mathrm{MgO}$ substrate derived from the same $123 \mathrm{gel}$, are shown as a function of the temperature. The inset shows the sharpness of the superconducting transition for the bulk ceramic.

2.2 CO-DOPED SAMPLES. - Samples of $\mathrm{YBa}_{2}$ $\mathrm{Cu}_{3-x} \mathrm{Co}_{x} \mathrm{O}_{7-y}$ were made [12] having values of $x$ ranging from 0 to 1 . The crystal data for this Codoped series is shown in figure 2. An orthorhombic (O) tetragonal $(\mathrm{T})$ transition occurs with increasing Co content. This also is observed for $\mathrm{Al}$ doped samples [12], suggesting that Co is trivalent as well. Within the same range of composition the unit cell volume increases (Fig. 2b), contrary to what is expected since $\mathrm{Co}^{+3}$ is smaller than $\mathrm{Cu}^{+2}$. The observed increase in oxygen content (determined iodometrically) upon Co doping (Fig. 2c) accounts for such an increase in the unit cell volume. Neutron experiments have shown $[13]$; 1) that Co is going onto the chains and adding
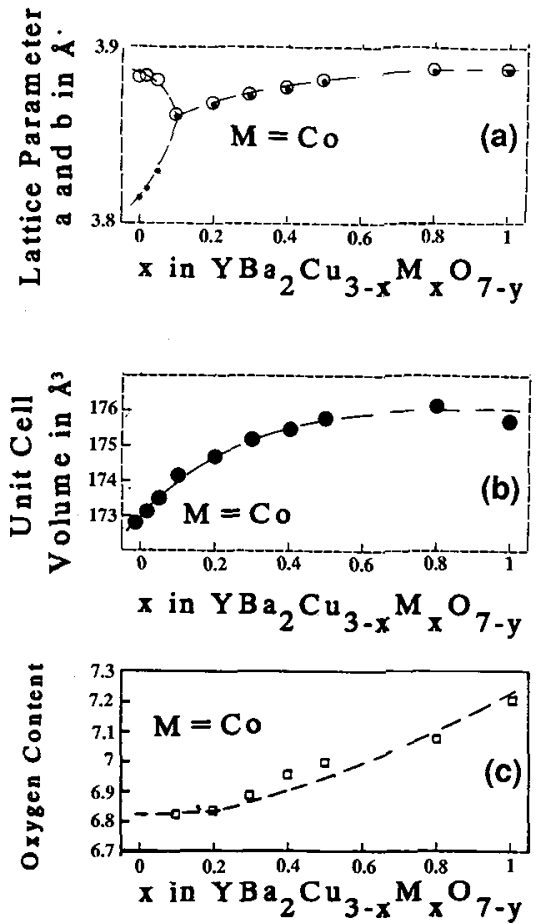

Fig. 2. - The lattice parameters $a$ and $b$ (curve a), the unit cell volume (curve b), and the oxygen content (curve c) are plotted as a function of $x$ for the $\mathrm{YBa}_{2} \mathrm{Cu}_{3-x} \mathrm{Co}_{x} \mathrm{O}_{7-y}$ series.

additional oxygen atoms in order to be octahedrally coordinated, and 2) that within the $\mathrm{Ba}-\mathrm{O}$ planes, upon Co substitution, the barium atoms move towards the plane and the oxygen towards the chains. Thus the planes and chains become electronically isolated swuch that, beyond $x=0.4$, the Co-doped samples are insulators.

In order to determine the Co valence, magnetic measurements were performed. Independent of the Co concentration, Curie-Weiss behavior was observed leading to a magnetic moment of $3.5 \mu \mathrm{B}$ (interval of the fit 40-300 K) per Co atom for superconducting and nonsuperconducting samples alike. This moment [12] does not correspond to high spin or low spin $\mathrm{Co}^{+3}$. There are several possibilities which could account for the Co reduced magnetic moment including an itinerant electron contribution, a partially ordered magnetic moment or an intermediate spin configuration. In the last case one would expect to observe an anomaly (a transition from medium-spin to high-spin) in the susceptibility temperature dependence at higher temperatures. Magnetic data for oxygen deficient Co samples over the range of temperature $4.2-900 \mathrm{~K}$ are shown in figure 3. The Co-doped sample $x=0.2$ follows a Curie-Weiss behavior over this temperature range, whereas an anomaly is observed around $450 \mathrm{~K}$ for the 


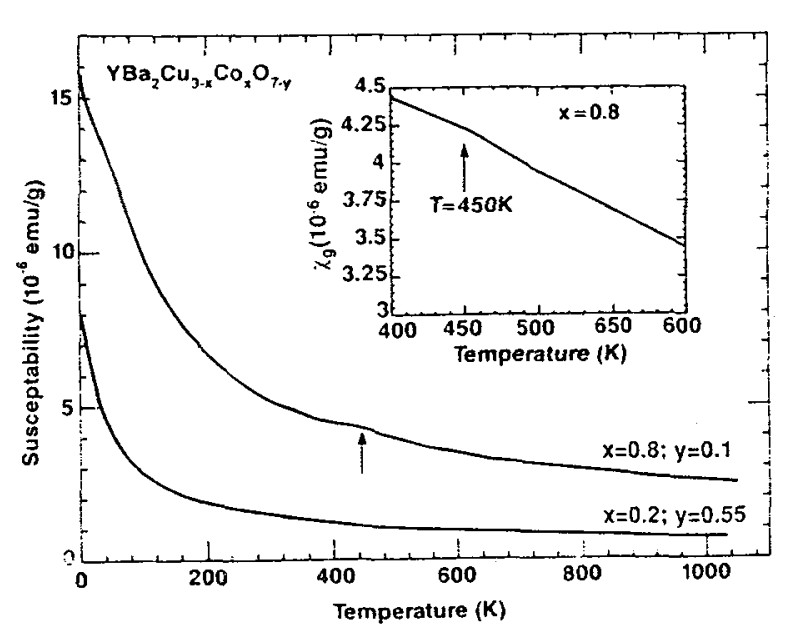

Fig. 3. - The magnetic susceptibility (in a field of $7.5 \mathrm{kG}$ ) as a function of temperature is shown for oxygen deficient Co samples. The part of the curve indicated by an arrow is enlarged in the inset.

$x=0.8$ Co-doped sample. Neutron diffraction data [14] have shown that this anomaly is associated with a magnetic ordering which is evidenced (on increasing the temperature) by the vanishing of the magnetic reflections $(1 / 2,1 / 2, L)$, with $L$ half integer only, at $T=435 \mathrm{~K}$.

In contrast to the magnetic data, which did not show any evidence for magnetic ordering for the $x=0.2 \mathrm{Co}$ doped sample, neutron diffraction measurements have revealed the presence of two sets of magnetic reflections $(1 / 2,1 / 2, L$ with $L=$ half or whole integer) at $5 \mathrm{~K}$ which vanish upon increasing the temperature. The loss of the $1 / 2$ integer $L$ reflections occurs at $T_{\mathrm{N} 2}=211 \mathrm{~K}$ whereas the the whole integral reflections remain up to $T_{\mathrm{N} 1}=415 \mathrm{~K}$. This contrasts with the 0.8 doped sample which shows only one magnetic transition; $T_{\mathrm{N} 1}=435 \mathrm{~K}$ for the half integral reflections. All the magnetic structures consist of magnetic $\mathrm{Cu}-\mathrm{O}$ sheets with the spins lying in the plane (i.e. perpendicular to the $c$-axis), but differ in the stacking sequence of these planes as indicated in figure 4 . To account for the intensity of the half integral reflections a magnetic moment on the $\mathrm{Cu}$ chain site has to be allowed, whereas such a moment is not required to fit the whole integral reflections. Note that for the $x=0.8$ Co-doped sample, the six $\mathrm{Cu}$ sites fully contribute to the spin structure. This may explain why the magnetic transition is only seen by susceptibility measurements in this sample and not in the $x=0.2$. It is interesting to recall that a magnetic ordering at $T_{\mathrm{N}}=40 \mathrm{~K}$, corresponding to half integral reflections, was recently observed for an insulating oxygen deficient 123 sample [15]. The above data shows that this magnetic ordering shifts towards higher temperatures with increasing

\section{$\left(\frac{1}{2} \frac{1}{2} \frac{3}{2}\right) \quad\left(\frac{1}{2} \frac{1}{2} 1\right)$}

$\left(\frac{1}{2} \frac{1}{2} \frac{3}{2}\right)$
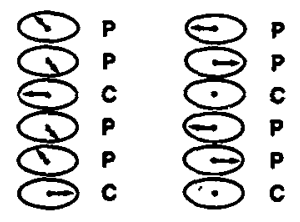

$\mathrm{T}_{\mathrm{N}_{2}=211 . \pm 6 . \cdot \mathrm{K}} \mathrm{T}_{\mathrm{N}_{1} \approx 415 . \pm 7 . \cdot \mathrm{K}}$
$\mathrm{YBa}_{2} \mathrm{Cu}_{2.8} \mathrm{Co}_{0.2} \mathrm{O}_{6.45}$

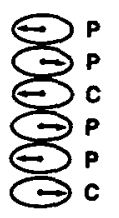

$\mathrm{T}_{\mathrm{N}_{2}=435 \pm 5}{ }^{* \mathrm{~K}}$

$\mathrm{YBa}_{2} \mathrm{Cu}_{2.2} \mathrm{CO}_{0.8} \mathrm{O}_{6.9}$

Fig. 4. - The orientation of the chain and plane spins is shown for each magnetic structure. Two magnetic structures are present in the $x=0.2$ Co-doped sample, in contrast to only one for the $x=0.8$ sample.

Co content, suggesting that there is an enhancement of the antiferromagnetic coupling between planes and chains.

\section{Bi-based materials}

3.1 SYNTHESIS, STRUCTURE AND PROPERTIES. - By heating (at $860^{\circ} \mathrm{C}$ ) several mixtures containing various ratios of powdered $\mathrm{Bi}_{2} \mathrm{O}_{3}, \mathrm{CaCO}_{3}, \mathrm{SrCO}_{3}$ and $\mathrm{CuO}$, we observed that the phase $\mathrm{Bi}_{4}(\mathrm{SrCa})_{6} \mathrm{Cu}_{4} \mathrm{O}_{16}$ is responsible for superconductivity at $85 \mathrm{~K}$ in the $\mathrm{Bi}$ system [7]. With a starting composition which contained an excess of both $\mathrm{Bi}_{2} \mathrm{O}_{3}$ and $\mathrm{CuO}$, crystals were obtained and $x$-ray single crystal studies showed that this Bi-phase has an ideal composition $\mathrm{Bi}_{4} \mathrm{Sr}_{4} \mathrm{Ca}_{2} \mathrm{Cu}_{4} \mathrm{O}_{16}$ and possesses a pseudotetragonal substructure, which can be viewed as a packing of $\mathrm{Bi}_{2} \mathrm{Sr}_{2} \mathrm{Ca}_{1} \mathrm{Cu}_{2} \mathrm{O}_{8}$ slabs the along $c$-axis. The slabs are separated by $3.2 \AA$ and shifted with respect to each other, giving this compound a layered character. Because of this lamelar character one would expect, as with other layered type materials, the occurence of other stacking sequences, the nature of which depends upon the thermal processing (temperature, annealing time, cooling rate) used. We succeeded in isolating two other phases [16], of general formula $\mathrm{Bi}_{2} \mathrm{Sr}_{2} \mathrm{Ca}_{n-1} \mathrm{Cu}_{n} \mathrm{O}_{y}$ with $n=1$ and 3 , by respectively heating a nominal composition 2201 (using $\mathrm{SrO}_{2}$ as the strontium source) in a sealed quartz ampoule at $T=850^{\circ} \mathrm{C}$, and by heating a $4334 \mathrm{com}$ position close to its melting point $\left(880^{\circ} \mathrm{C}\right)$ for several days to prepare the 2223 phase. The three $\mathrm{Bi}$ phases with $n=1,2$ and 3 were found to superconduct at $10 \mathrm{~K}, 85 \mathrm{~K}$ and $110 \mathrm{~K}$ respectively. Their structures (shown in Fig. 5) are simply related. The basis unit subcell is pseudotetragonal having the same a-axis, but with a different $c$-axis. The observed increase in the $c$-axis from $24.6 \AA(n=1)$ to $30.6 \AA(n=2)$ and $37.1 \AA(n=3)$ results from the progressive addition of $2 \times 1$ and $2 \times 2 \mathrm{CaCuO}_{2}$ slabs, each about $3 \AA$ 


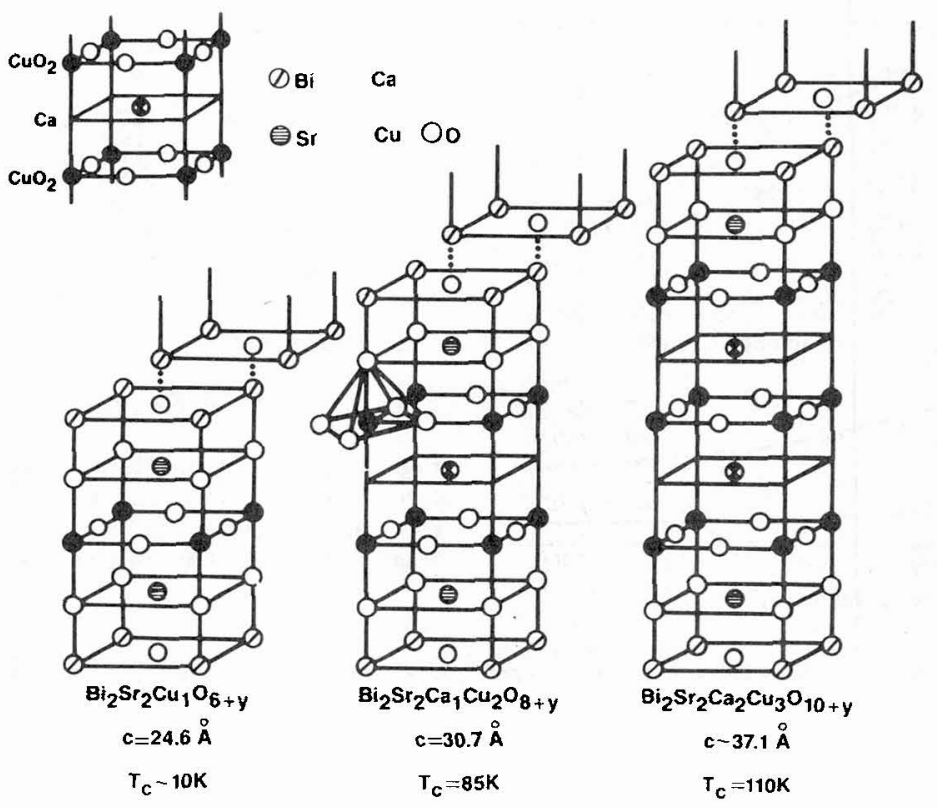

Fig. 5. - Crystal substructures for the $\mathrm{Bi}$ phases of general formula $\mathrm{Bi}_{2} \mathrm{Sr}_{2} \mathrm{Ca}_{n-1} \mathrm{Cu}_{n} \mathrm{O}_{y}$ with $n=1,2$ and 3 . The repeat unit $\mathrm{CaCuO}_{2}$ is shown in the top left corner.

thick, to the stacking sequence in the unit cell. As with other layered-type materials we find, by means of high resolution electron microscopy (HREM), that stacking faults are common imperfections in these materials [16]. We believe that these imperfections are the origin of the wide range $(10 \mathrm{~K})$ of $T_{\mathrm{c}}^{\prime} \mathrm{s}$ obtained for compounds of the same nominal composition but processed differently.

3.2 Chemical substitution. - It is well established that the non-superconducting parent compounds of the $40 \mathrm{~K}$ and $90 \mathrm{~K}$ materials are antiferromagnetic. Thus it is important to determine whether this experimental observation is still valid with the new Bi phases. Several heating processes and chemical substitutions have been tried in an attempt to reach the insulating regime without destroying the parent structure. With the $n=1$ phase we find that materials heated at $890 \mathrm{C}$ are superconductors whereas those heated at $850 \mathrm{C}$ are semiconductors, without a noticeable change in stoichiometry. No evidence for magnetic ordering up to $400 \mathrm{~K}$, as determined by magnetic measurements, was observed in the semiconducting samples. The $n=2$ phase remains superconducting at $85 \mathrm{~K}$ independent of the ambient (air, oxygen, argon) used during the firing process. Thus, we have investigated the possibility of cation substitution in this phase (although this is complicated because of the possible substitution of $\mathrm{Sr}$ in the $\mathrm{Ca}$ sites and vice versa [7]) to achieve a semiconducting regime.
By analogy to the $40 \mathrm{~K}$ material $\left(\mathrm{La}_{2-x} \mathrm{Sr}_{x} \mathrm{CuO}_{4}\right)$ [17], the exchange of Sr by La within the $n=2$ phase has been performed with the objective being a decrease in the amount of $\mathrm{Cu}^{+3}$ thereby generating a semiconducting-like behavior. But what we obtained, however, was a multiphase material with the $n=1$ phase being the major phase. This indicate that a $n=1$ phase in which $\mathrm{Sr}$ is replaced by $\mathrm{La}$ and $\mathrm{Ca}$, exists as a single phase. Based on the fact that $\mathrm{Ca}$ and $Y$ occupy identical crystallographic sites in both types of materials [18], the substitution of Ca by rare earths appears quite likely. We found, in accordance with the observations of others [19-20] (in studying the $\mathrm{Bi}_{4} \mathrm{Sr}_{4} \mathrm{Ca}_{3-x} \mathrm{M}_{x} \mathrm{Cu}_{4} \mathrm{O}_{3} ; \mathrm{M}=\mathrm{Tm}, \mathrm{Lu}$ ) that this type of substitution is successful. Figure 6 shows the results for the thulium substitution only. The samples are single phase up to $x=2$ and multiphase for $x$ greater than 2, so that the data are not reported for this range of composition. Upon increasing the $T_{\mathrm{m}}$ content the $c$-axis parameter decreases continuously whereas both the $a$-lattice parameter and unit cell volume $(V)$ do'not (Fig. 6a). Note that the $T_{\mathrm{m}}$ substitution produces a semiconducting material $\left(T_{c}<4.2 \mathrm{~K}\right.$ beyong $\left.x=1\right)$ and that simultaneously the oxygen content in the material increases whereas through this range of solubility the amount of $\mathrm{Cu}(\mathrm{III})$ (determined by chemical analysis [7]) remains roughly constant. This situation is similar to Co substitution in the $\mathbf{1 2 3}$ material discussed above, where Co atoms add additional oxygen atoms. Experiments are in progress to determine whether magnetic interactions exist within the insulating $\mathrm{Bi}$ phases. 

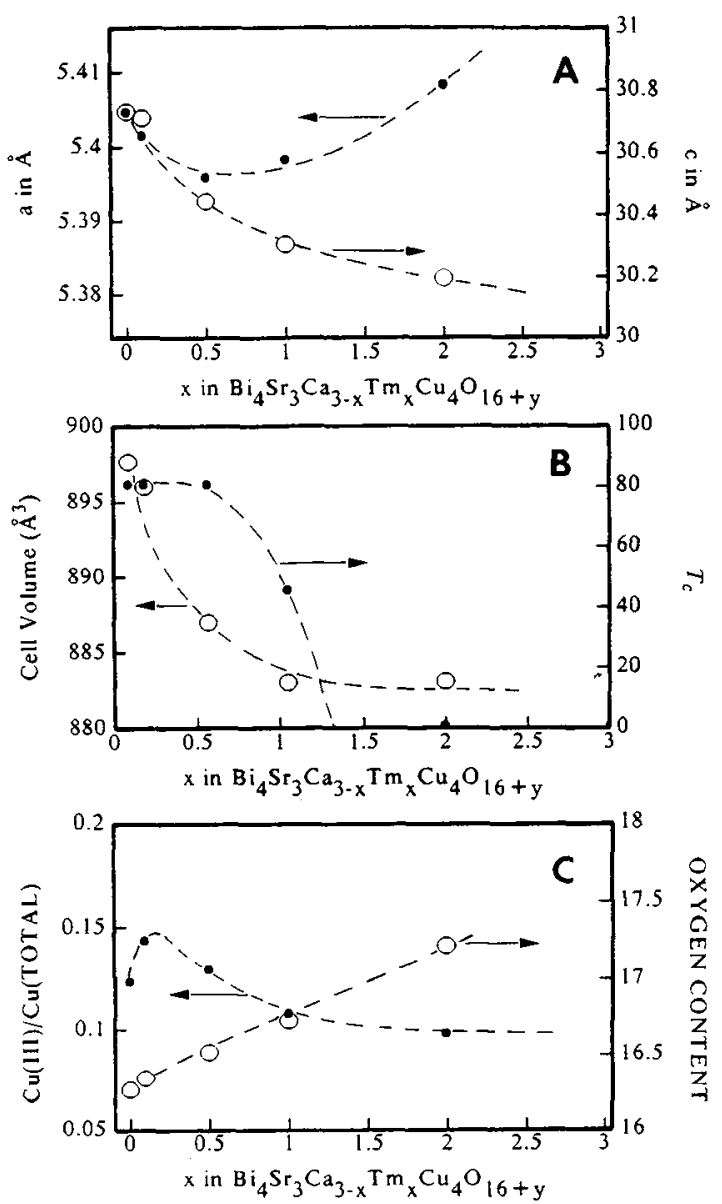

Fig. 6. - The lattice parameters $a$ and $c$ (A), the unit cell volume $V$ and critical temperature $T_{c}$ (determined by the onset of the AC-susceptibility signal) (B), and the oxygen content and number of $\mathrm{Cu}$ (III) per total $\mathrm{Cu}(\mathrm{C})$ are shown as a function of $x$ for the $\mathrm{Bi}_{4} \mathrm{Sr}_{3} \mathrm{Ca}_{3}-x \mathrm{Tm}_{x} \mathrm{O}_{y}$ series.

Finally, in contrast to the 123 system, we find that the substitution for $\mathrm{Cu}$ by $3 \mathrm{~d}$ metals within the $85 \mathrm{~K}$ phase always results in a multiphase product.

3.3 Preparation via SOlUtion techniques. - Our synthesis studies of the 123 material indicated that solution techniques were producing better materials. With this in mind, and with the hope of preparing materials free of intergrowths, we developed a solution technique to prepare the Bi phases in a thick film form and further extended this process to prepare Tl-based materials [21]. The principle of our solution technique consists of properly complexing the $\mathrm{Bi}$ and $\mathrm{Tl}$. The main feature of this procedure is to dissolve the $\mathrm{Bi}$ salt (e.g. nitrate) in a 1 to a ratio solution of water and glycerol. The salts of the other elements $\left(\mathrm{Cu}\left(\mathrm{NO}_{3}\right)_{2}\right.$, $\mathrm{Sr}\left(\mathrm{NO}_{3}\right)_{2}, \mathrm{Ca}(\mathrm{OH})_{2}$ and $\left.\mathrm{Ca}\left(\mathrm{NO}_{3}\right)_{2}\right)$ are then added to the above solution to reach the desired composition (e.g. 4334). Thick films (1 to 10 microns) were obtained either by dipping the substrate into the viscous solution or by spraying the solution onto a hot substrate. The firing process required to obtain superconducting thick films of the $\mathrm{Bi}$ and Tl-based materials is different because of the greater volatility of the $\mathrm{Tl}$ as compared to the $\mathrm{Bi}$. Firing at $880 \mathrm{C}$ for about 5 minutes followed by quenching is usually sufficient to obtain a $75 \mathrm{~K}$ superconducting Bi film. With the $\mathrm{Tl}$ material, an intermediate heating at $500 \mathrm{C}$ is required to remove the organic component prior to a 3 minutes firing at $890 \mathrm{C}$ in a sealed $\mathrm{Pt}$ tube containing a small amount of $\mathrm{Tl}$ bulk phase (to maintain the $\mathrm{Tl}$ vapor pressure). The Tc's of the resulting Bi- and Tl- based films are $75 \mathrm{~K}$ and $105 \mathrm{~K}$ respectively (Fig. 7 ). In both systems the deposited films are highly oriented, as indicated by the X-ray diffraction patterns (Fig. 8) which show only the 001 Bragg peaks, demonstrating that the $c$-axis is perpendicular to the substrate. Among

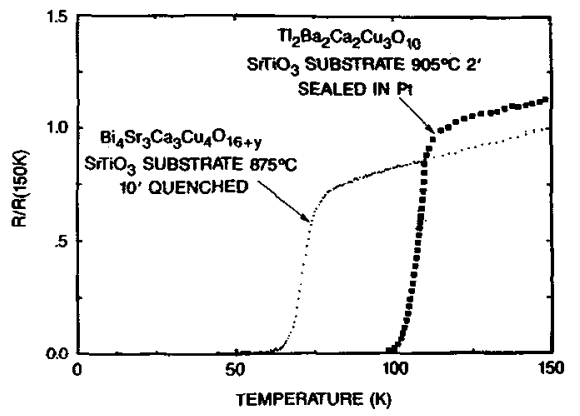

Fig. 7. - Temperature dependence of the resistance for thick films of Bi-based and Tl-based cuprates. The thicknesses are 4 and 2.5 microns for the $\mathrm{Bi}$ and $\mathrm{Tl}$ films respectively.
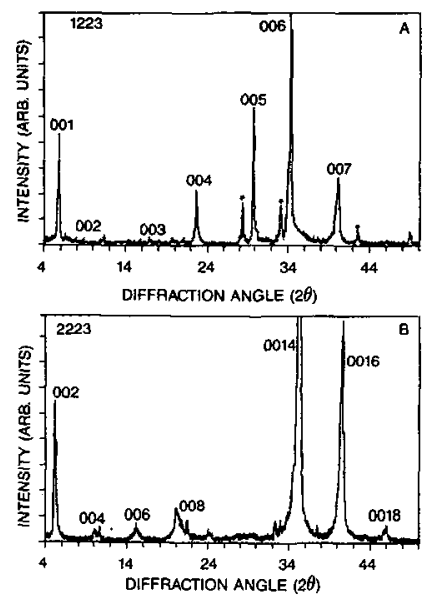

Fig. 8, - X-ray diffraction for thallium-based thick films obtained from a glycerol solution of 2223 starting composition sprayed onto a $\mathrm{SrTiO}_{3}$ substrate and fired at $925^{\circ} \mathrm{C}$ for 5 minutes (curve $A$ where only the phase 1223 is observed) and 2 minutes (curve $B$ where only the 2223 phase is abserved). The Bragg peaks denoted by asterisks are related to the substrate or are unidentified. 
the substrates investigated $\left(\mathrm{Al}_{2} \mathrm{O}_{3}, \mathrm{ZrO}_{2}, \mathrm{MgO}\right.$, and $\mathrm{SrTiO}_{3}$ ), the best results (highest $T_{\mathrm{c}}$ and less substrate reaction) were obtained with $\mathrm{SrTiO}_{3}$. Depending upon the cation concentration of the starting solutions and the heating process used, single phase thick films of the 2201 and 2212 Bi-compounds, and thick films of the 2212,2223 , and $1223 \mathrm{Tl}$ phases were obtained. We observe that in the $\mathrm{Tl}$ system the easiest phase to obtain via the solution technique is 1223 , whereas this phase is the most difficult to obtain by solid state reaction. A possible explanation for this difference is the reaction kinetics; compound formation takes hours in the solid state process whereas it occurs within seconds when starting from solution precursors. This again confirms that solution chemistry holds promise for preparing metastable phases, having some major advantages over the solid state reaction process. However, a remaining drawback is that the superconducting films obtained have a low critical current (about $50 \mathrm{Amp} / \mathrm{cm}^{2}$ ) indicating that further work is required to fully optimize this process of interest for technological applications.

\section{Acknowledgments}

We would like to thank J. M. Rowell and J. H. Wernick for helpful discussions as well as J. Waszczak and L. F. Schneemeyer for performing high temperature susceptibility measurements.

[1] Bednorz, J. G. and Muller, K. A., Z. Phys. B 64 (1986) 189.

[2] Wu, M. K., Ashburn, J. R., Torng, C. J., Hor, P. H., Meng, R. L., Gao, L., Huang, Z. J., Wang, Y. Q. and Chu, C. W., Phys. Rev. Lett. $\mathbf{5 8}$ (1987) 908.

[3] Le Page, Y., McKinnon, W. R., Tarascon, J. M., Greene, L. H., Hull, G. W. and Hwang, D. M., Phys. Rev. B 35 (1987) 7115.

[4] Vaknin, D., Sinha, S. K., Moncton, D. E., Johnston, D. C., Newsam, J. M., Safinya, C. R. and King, H. E., Phys. Rev. Lett. 58 (1987) 2802; Tranquada, J. M., Cox, D. E., Kunnmann, W., Moudden, H., Shirane, G., Suenaga, M., Zolliker, P., Vaknin, D., Sinha, S. K., Alvarez, M. S., Jacobson, A. J. and Johnston, D. C., Phys. Rev. Lett. 60 (1988) 156.

[5] Anderson, P. W., Science 235 (1987) 1196.

[6] Maeda, H., Tanaka, Y., Fukutomi, M. and Asano, T., Jpn J. Appl. Phys. Lett. 27 (1988) L209.
[7] Tarascon, J. M., LePage, Y., Barboux, P., Bagley, B. G., Greene, L. H., McKinnon, W. R., Hull, G. W., Giroud, M. and Hwang, D. M., Phys. Rev. $B 37$ (1988) 9382.

[8] Barboux, P., Tarascon, J. M., Greene, L. H., Hull, G. W. and Bagley, B. G., J. Appl. Phys. 63 (1988) 2725.

[9] Barboux, P., Tarascon, J. M., Bagley, B. G., Greene, L. H., Hull, G. W., Meagher, B. W. and Eom, C. B., Mat. Res. Symp. Proc. 99 (1988) 49.

[10] Tarascon, J. M., Greene, L. H., Bagley, B. G., McKinnon, W. R., Barboux, P. and Hull, G. W., Novel Superconductivity, Eds. S. A. Stuart and V. Z. Kresin (Plenum Press, New York and London) 1987, p. 705.

[11] Gurvitch, M. and Fiory, A. T., in Novel Superconductivity, Eds. S. A. Wolf and V. Z. Kresin (Plenum Press, New York) 1987, p. 663.

[12] Tarascon, J. M., Barboux, P., Miceli, P., Greene, L. H. and Hull, G. W., Phys. Rev. B 37 (1988) 7458.

[13] Miceli, P. F., Tarascon, J. M., Greene, L. H., Barboux, P., Rotella, F. J. and Jorgenson, J. D., Phys. Rev. B 37 (1988) 5932.

[14] Miceli, P. F., Tarascon, J. M., Greene, L. H., Barboux, P., Giroud, M., Neumann, D. A., Rhyne, J. J., Schneemeyer, L. F. and Waszczak, J. V., Phys. Rev. B 38 (1988) 9209.

[15] Kadowaki, H., Nishi, M., Yamada, Y., Takeya, H., Takei, H., Shapiro, S. M. and Shirane, G., Phys. Rev. B 37 (1988) 7932.

[16] Tarascon, J. M., McKinnon, W. R., Barboux, P., Hwang, D. M., Bagley, B. G., Greene, L. H., Hull, G. W., LePage, Y., Stoffel, N. and Giroud, M., Phys. Rev. B 38 (1988) 8885.

[17] Tarascon, J. M., Greene, L. H., McKinnon, W. R., Hull, G. W. and Geballe, T. H., Science 235 (1987) 1373.

[18] Tarascon, J. M., Barboux, P., Greene, L. H., Bagley, B. G., Hull, G. W., LePage, Y. and McKinnon, W. R., Proc. of the Inter. Conf. Mater. and Mechanisms of Superconductivity; High-Temperature Superconductivity (Interlaken, Switzerland) February 29-March 4, reprinted from Physica $C$, Vols. 153-155.

[19] Fukushima, N., Niu, H. and Andlo, K., Jpn J. Applied Phys. 27 (1988) L790.

[20] Manthiram, A. and Goodenough, J. B., Appl. Phys. Lett. 53 (1988) 420.

[21] Barboux, P., Tarascon, J. M., Shokoohi, F., Wilkens, B. J. and Schwartz, C. L., J. Appl. Phys., in press. 